Chapter 4

\title{
Search for Environmentally Friendly Technology for Processing Molybdenum Concentrates
}

\author{
E.I. Kharin, N.A. Vatolin, B.D. Khalezov and \\ E.A. Zelenin \\ Additional information is available at the end of the chapter
}

http://dx.doi.org/10.5772/60671

\begin{abstract}
At the Institute of Metallurgy, Ural Branch, Russian Academy of Sciences, a search has been carried out for the oxidative annealing of the molybdenum sulfide concentrate of the new Yuzhno-Shameiskoe deposit with calcium-containing additives. As a result, sulfurous gas transforms into calcium sulfate and does not evolve into the gas phase. In calcine, molybdenum and rhenium remain complete as calcium molybdate and perrhenate. The principles of the selective desalination of molybdenum and rhenium from calcine have been studied. Processes of their recovery from solutions have been studied.
\end{abstract}

Keywords: oxidation, desalination, molybdenum, rhenium

\section{Introduction}

Molybdenum rocks, which have found industrial applications, are represented by molybdenite. Molybdenum can be simultaneously recovered from polymetal rocks, which relate to copper-molybdenum, tungsten-molybdenum, lead-molybdenum, and vanadium-molybdenum. After the corresponding steps of enrichment, these rocks are molybdenum concentrates. The enrichment of molybdenum rocks is mainly performed according to cooperative or selective flotation. Oxidized molybdenum rocks, which have poor enrichment ability according to flotation and, finally, all possible waste, tails, and cakes from processing rocks and 
concentrates that have a large fraction in metallurgy of molybdenum, exist in the largest amounts [1].

The main methods of processing molybdenum sulfide concentrates correspond to the annealing of concentrate with the subsequent preparation of ferromolybdenum according to silicothermy, reduction with carbon, and aluminothermy; annealing with subsequent desalination by various solvents, e.g., ammonia, solutions of hydroxides, and alkali metal carbonates; annealing with the additional charging of the lime or iron scale with the production of calcium molybdate or iron molybdate for subsequent preparation of ferromolybdenum; annealing with the deposition of molybdenum trioxide; sintering with soda, as well as sodium sulfide or sulfate with coal and subsequent desalination, the precipitation of molybdenum sulfide (applied to oxidized molybdenum rocks, e.g., those that contain wulfenites); chloride deposition with sodium chloride or direct chlorination (applied to polymetal rocks containing molybdenum); and hydrometallurgical methods, more specifically, autoclave, using nitric acid at elevated pressure and temperature or use of oxygen, as well as using alkali metals at normal temperatures and pressure.

The first and most important step in the processing of molybdenum concentrate is annealing. When it enters processing, molybdenum concentrate contains $75-95 \%$ molybdenum and rhenium sulfide, as well as accompanying copper, iron, zinc, and lead sulfides, and impurities, namely, silicon and aluminum oxides and calcium and magnesium carbonates. Molybdenum concentrate contains 45-55\% molybdenum and 30-35\% sulfur. Annealing is required in order to eliminate all sulfur. Sulfate and sulfide sulfurs, which exist in the annealed concentrate, are also unacceptable because they easily dissolve and contaminate the solutions obtained in the subsequent hydrometallurgical treatment of calcines. In the formation of oxidative atmosphere, all free carbon, oils, and fluororeagents should be burned from concentrate. Among fluororeagents, the removal of collectors that coat sulfides and oxides by the film, making them hydrophobic, is particularly necessary. A decrease in the wettability of the concentrate results in a decrease in the recovery of molybdenum to solution in hydrometallurgical processing [2, 3].

Rhenium is found in most molybdenum concentrates. In industry, sources of rhenium (by $80 \%$ ) are molybdenum and copper sulfide concentrates; the remaining amount is obtained by recycling Re-Pt catalysts. Upon the enrichment of copper-molybdenum rocks, Re follows Mo, which is often accompanied by $\mathrm{Cu}$. During flotation, up to $80 \%$ of Re enters the concentrate. For example, molybdenum concentrates obtained by enriching porphyry copper rocks contain $0.005-0.075 \%$ Re. The oxidative annealing of molybdenum sulfide concentrates is performed at $550-650^{\circ} \mathrm{C}$.

In order to anneal molybdenum concentrates, the following setups are conventionally used: muffle and batch-type furnaces with manual raking of calcine, rotary tubular furnaces, multiple-bed furnaces, and fluidized-bed furnaces.

In concentrate, rhenium forms $\operatorname{Re}_{2} \mathrm{O}_{7}$, which is taken away by the gas flow. The trapping of metal is performed using special wet systems (scrubbers and bubblers) in combination with dry setups (cyclones and sleeve filters), which can trap 60-70\% Re. Rhenium is recovered 
according to various methods. Rhenium is recovered from solutions as $\mathrm{Re}_{2} \mathrm{~S}_{7}$ by sodium sulfide, ammonium sulfide, and polysulfides, as well as in the form of potassium perrhenate $\mathrm{KReO}_{4}$ by $\mathrm{KCl}$ solution. Re is selectively sorbed from sulfuric acid solutions with subsequent elution by an aqueous solution of ammonia and the vaporization of elutes, which results in ammonium perrhenate. The combined extraction of rhenium and molybdenum by tertiary amines from sulfuric acid solutions, ammonia reextraction of Re and Mo, the lime purification of reextract from $\mathrm{Mo}$, and the vaporization and formation of ammonium perrhenate are suggested.

Existing national and foreign technologies of processing of molybdenum concentrates and industrial products involve oxidative annealing with the evolution of sulfurous gas to gas phase, more than half of rhenium as $\mathrm{Re}_{2} \mathrm{O}_{7}$, and part of molybdenum as $\mathrm{MoO}_{3}$. This creates ecological problems and gives rise to noncollectable losses of metals. In addition, the subsequent hydrometallurgical processing of annealed product results in the formation of waste water and is extremely technically complicated when preparing pure products, e.g., ammonium paramolybdate $\left(\left(\mathrm{NH}_{4}\right)_{6} \mathrm{Mo}_{7} \mathrm{O}_{24} \cdot 4 \mathrm{H}_{2} \mathrm{O}\right)$ and ammonium perrhenate $\left(\mathrm{NH}_{4} \mathrm{ReO}_{4}\right)$. The fact is that, at the desalination of annealed concentrate, in addition to Mo and Re, there are a large number of harmful impurities in solutions, the purification from which leads to the additional noncollectable loss of Mo and Re. As a result, no more than $50-60 \%$ Re and $90-97 \%$ Mo is extracted to trade products [4-6]. Existing technology for processing molybdenum concentrates is given in Fig. 1.

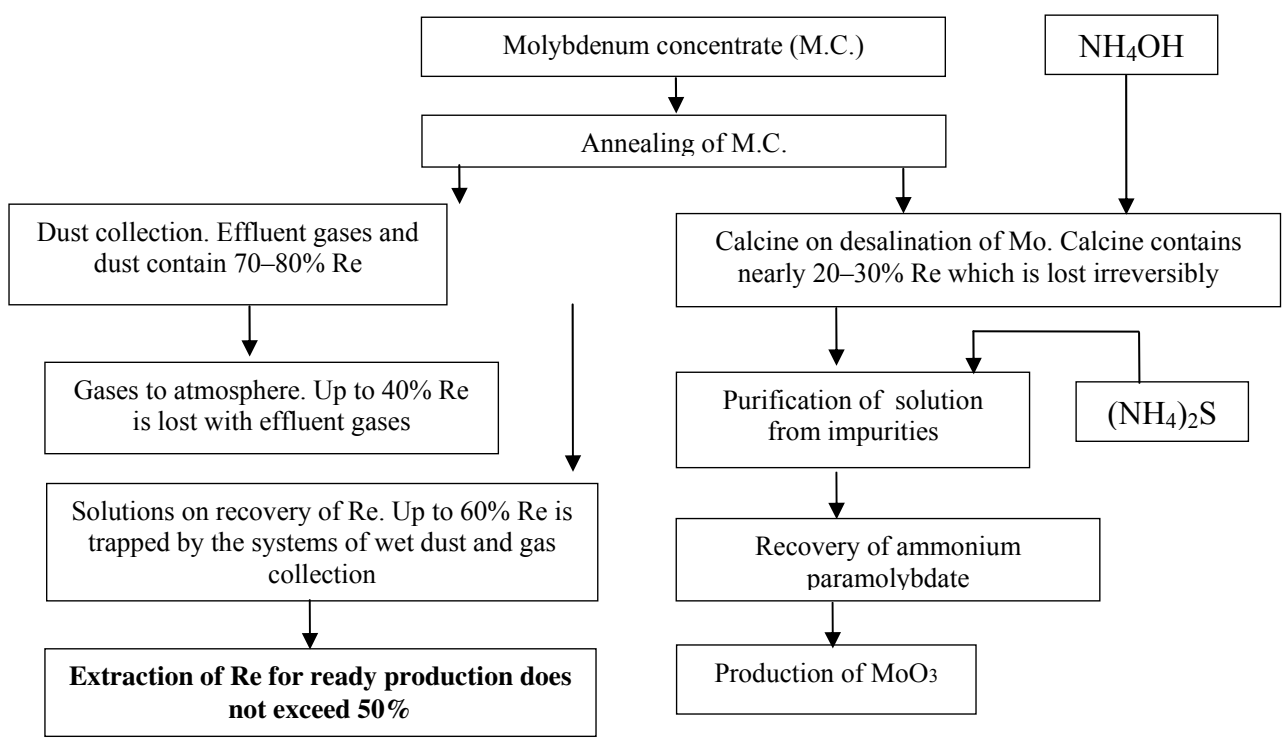

Figure 1. Flow diagram of processing molybdenum sulfide concentrates

Substantial losses of molybdenum and rhenium when processing molybdenum raw material determine the demand for developing improved technology. 


\section{Results and discussion}

At the Institute of Metallurgy, the search for the oxidative annealing of molybdenum sulfide concentrate of the new Yuzhno-Shameiskii deposit was performed (table 1). Concentrate was obtained by enriching rock recovered from an exploratory career [7].

\begin{tabular}{ccccccccccc}
\hline Element & $\mathbf{M o}$ & $\mathrm{SiO}_{2}$ & $\mathrm{As}$ & $\mathrm{Sn}$ & $\mathrm{P}$ & $\mathrm{Cu}$ & $\mathrm{V}$ & $\mathrm{Al}$ & - \\
\hline wt $\%$ & $\mathbf{4 2 , 6}$ & 14,3 & 0,0035 & 0,0016 & 0,02 & $\mathbf{2 , 0 7}$ & 0,2 & 0,9 & - \\
\hline Element & $\mathrm{Ca}$ & $\mathrm{Mg}$ & $\mathrm{Fe}$ & $\mathrm{Pb}$ & $\mathrm{W}$ & $\mathrm{Zn}$ & $\mathrm{S}$ & $\mathrm{Cr}$ & $\mathbf{R e}$ \\
\hline wt $\%$ & 0,36 & 0,459 & 4,86 & 0,118 & 0,044 & 0,046 & 31,7 & 0,011 & $\mathbf{0 , 0 0 4}$ \\
\hline
\end{tabular}

Table 1. Composition of concentrate

Concentrate was annealed with calcium-containing additives. As a result, sulfurous gas is transformed into calcium sulfate and does not evolve into the gas phase as follows:

$$
\mathrm{SO}_{2}+\mathrm{CaO}+1 / 2 \mathrm{O}_{2}=\mathrm{CaSO}_{4}
$$

In calcine, molybdenum and rhenium remain completely as calcium molybdate and perrhenate:

$$
\begin{aligned}
& \mathrm{MoO}_{3}+\mathrm{CaO}=\mathrm{CaMoO}_{4} ; \\
& \operatorname{Re}_{2} \mathrm{O}_{7}+\mathrm{CaO}=\mathrm{Ca}\left(\mathrm{ReO}_{4}\right)_{2}
\end{aligned}
$$

The conditions of annealing are as follows: the temperature must be $550-650^{\circ} \mathrm{C}$, the time of annealing must be 60-90 $\mathrm{min}$, and a content of calcium-containing additive in excess of what is stoichiometrically required to bind sulfur, molybdenum, and rhenium. The $\mathrm{SO}_{2}$ content in effluent gases was determined by an MGL_19.3A gas analyzer. The maximum allowable concentration of $\mathrm{SO}_{2}$ in effluent gases is $0-2.5 \mathrm{mg} / \mathrm{m} 3$.

Effluent gases were passed through alkali solution for trapping rhenium. The rhenium content in the solution was determined qualitatively according to calorimetry based on the formation of a brown-yellow rhenium compound with rhodanide, $\mathrm{ReO}$ (CNS). This compound is formed when treating the solution with a mixture of $\mathrm{SnCl}_{2}$ and $\mathrm{KCNS}$ [8]. According to the analysis, rhenium was not detected in the solution.

$$
\mathrm{ReO}_{4}{ }^{-}+\mathrm{Sn}^{2+} 4 \mathrm{CNS}^{-}+4 \mathrm{H}^{+} \rightarrow\left[\mathrm{ReO}_{2}(\mathrm{CNS})_{4}\right]^{3-}+\mathrm{Sn}^{4+}+2 \mathrm{H}_{2} \mathrm{O}
$$

The methods of selective desalination of rhenium and molibdenum from the calcine obtained were worked out. Firstly, rhenium is bleached selectively. Desalination solutions contain 4.74 
$\mathrm{mg} / \mathrm{dm}^{3} \mathrm{Re}, 4.5 \mathrm{mg} / \mathrm{dm}^{3} \mathrm{Mo}, 520.5 \mathrm{mg} / \mathrm{dm}^{3} \mathrm{~S}$, and $460.5 \mathrm{mg} / \mathrm{dm}^{3}$ Ca. Degree of extraction of rhenium to solution of $76 \%$ was achieved.

In order to recover rhenium from solutions, sorption method was used. Five sorbents were tested, namely, AH31, ABI7, AMP, Purolite A170 (further A170), and Purolite A172 (further A172). Sorption was performed under dynamic conditions (table 2).

\begin{tabular}{ccc}
\hline sorbent & Dynamic volume capacity, $\mathbf{g} / \mathbf{d m}^{3}$ & Full dynamic volume capacity, $\mathbf{g} / \mathbf{d m}^{3}$ \\
\hline AH-31 & 57,8 & 63,8 \\
\hline AMП & 68,2 & 74,2 \\
\hline AB-17 & 72,4 & 79,1 \\
\hline A-170 & 75,0 & 82,5 \\
\hline A-172 & 88,1 & 95,8 \\
\hline
\end{tabular}

Table 2. Capacity characteristics of anion exchangers

As follows from the results of study of sorption on five brands of anionites, A170 and A172 have the highest capacity on rhenium. However, A170 anionite with rhenium sorbs a substantial amount of molybdenum; this does not satisfy to the requirements on rhenium selectivity in the presence of molybdenum. Regarding A172 anionite, it almost does not sorb molybdenum. Desorption of rhenium was performed by $10 \%$ aqueous solution of ammonia. Degree of desorption of rhenium from A170 and A172 anionites was less than 98\% (table 3) after passing three to four specific volumes of eluting solution (concentration of rhenium in desorbates is $6.3 \mathrm{~g} / \mathrm{dm}^{3}$ ), and degree of desorption from AH31, ABI7, and AMP anionites was less than $20 \%$ (rhenium concentration in desorbates is $0.5-1 \mathrm{~g} / \mathrm{dm}^{3}$ ).

The results of sorption of rhenium from the leaching solution cakes M.C. on ion exchanger Purolite A-172 shown the high efficiency of the sorption process for the recovery of rhenium from the leaching solution.

\begin{tabular}{ccccc}
\hline $\begin{array}{c}\text { Element } \\
\text { Name }\end{array}$ & Re & Mo & S & Ca \\
\hline Leach solution $\mathbf{R e}, \mathbf{m g} / \mathbf{d m}^{3}$ & 130,0 & 60,36 & 6290,0 & 717,0 \\
\hline Desorbate, $\mathbf{m g} / \mathbf{d m}^{3}$ & 6260,0 & 2,35 & 571,4 & 226,8 \\
\hline
\end{tabular}

Table 3. Composition of solutions before sorption and desorption on A-172

Of the stripping solution was obtained by crystallization rough ammonium perrhenate with a rhenium content of $69.2 \mathrm{wt}$. \%, which corresponds to the brand AR-0. After purification of crude perrhenate was obtained pure ammonium perrhenate with a rhenium content of 69.3 wt. \%, molybdenum, calcium and sulfur is less than $0.001 \mathrm{wt}$ \%, which corresponds to the brand AR-00.

After the desalination of rhenium, cakes were treated with an aqueous solution of soda at a concentration of $250 \mathrm{~g} / \mathrm{dm}^{3}$ for 30-90 min (Fig. 2). Conditions of desalination of molybdenum 
are as follows: sodium carbonate solution with the concentration from 150 to $200 \mathrm{~g} / \mathrm{dm}^{3}$, temperature is $90^{\circ} \mathrm{C}$, time is $60 \mathrm{~min}$, and solid-to-liquid phase ratio is 1:4. Desalination solutions contain $0.75 \mathrm{mg} / \mathrm{dm}^{3}$ Re, $32.48 \mathrm{~g} / \mathrm{dm}^{3} \mathrm{Mo}, 53.5 \mathrm{~g} / \mathrm{dm}^{3} \mathrm{~S}$, and $40.9 \mathrm{mg} / \mathrm{dm}^{3}$ Ca. Complete reextraction of rhenium and recovery of molybdenum to solution to the degree of $99.8 \%$ was achieved [10]. The technology for processing molybdenum concentrates developed is given in Fig. 3.

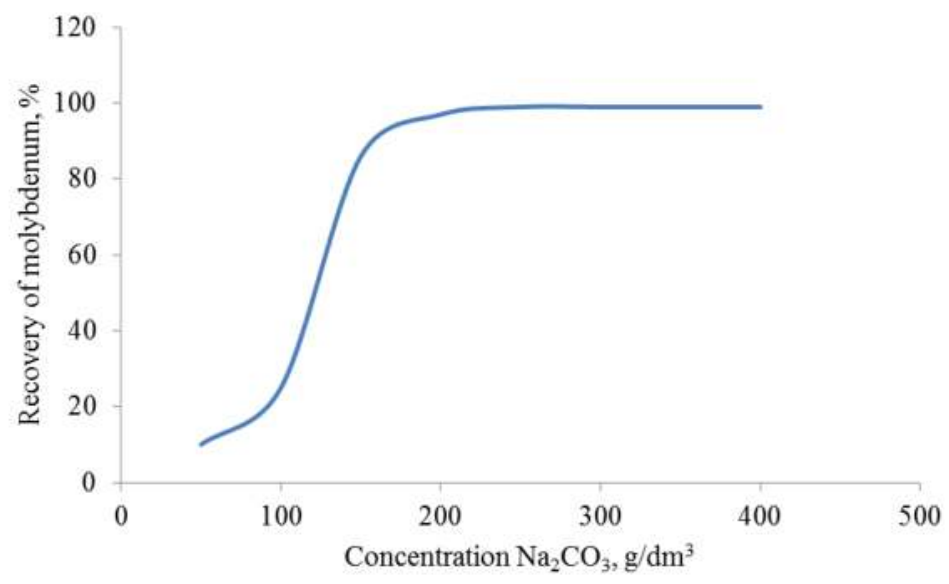

Figure 2. Recovery of molybdenum vs. concentration of soda

\section{Conclusions}

Existing national and foreign technologies of processing of molybdenum concentrates and industrial products do not enable one to recover rhenium completely and are not ecologically effective. No more than 50 to $60 \%$ Re and 90 to $97 \%$ Mo are recovered to trade products.

On the laboratory scale, the conditions of the oxidative annealing of molybdenum concentrate with the addition of $\mathrm{CaO}$ without the evolution of sulfurous gas in gas phase and the loss of volatile compounds of molybdenum and rhenium were determined. The methods of the selective desalination of rhenium and molybdenum were devised based on the calcine obtained. First, rhenium is bleached selectively; then, molybdenum is bleached by alkali metal carbonate with a concentration of $150-250 \mathrm{~g} / \mathrm{dm}^{3}$. Sodium or potassium carbonate is used as alkali metal carbonate. The degree of recovery of molybdenum takes the value of $99.8 \%$. Degree of selective recovery of rhenium to solution at the first step is $76 \%$ and remaining $23.8 \%$ is bleached at the second step together with molybdenum. The selective desalination of these metals is a prerequisite for the preparation of high-quality molybdenum and rhenium products. 
A principally new direction in the development of environmentally friendly technology of production of molybdenum and rhenium from molybdenum-containing concentrates and industrial products was found. The results of the studies are considered for use at the new Yuzhno-Shameiskii deposit and modernization of existing productions. The demand for molybdenum and rhenium used for doping titanium alloys increases due to the creation of Titanium Valley in the Urals. Molybdenum and rhenium have recently been purchased abroad because national industry does not fabricate this production.

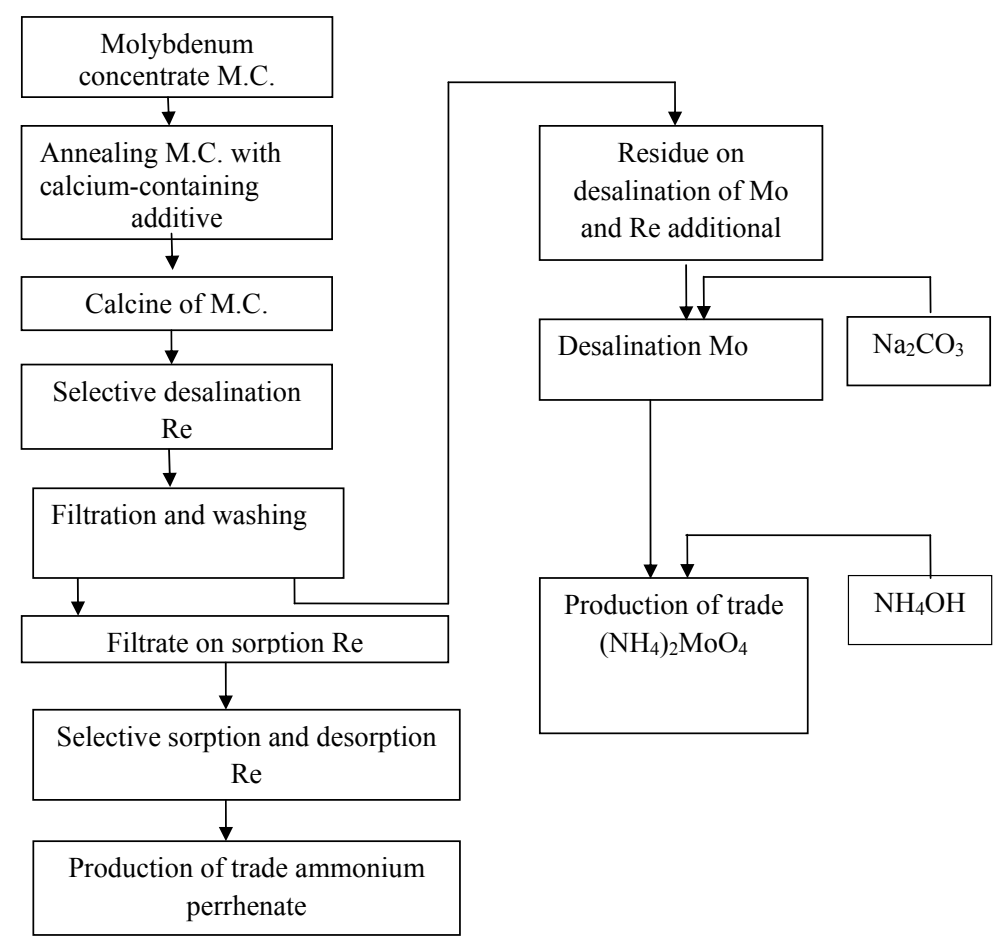

Figure 3. Flow diagram of processing molybdenum concentrates

\section{Author details}

E.I. Kharin*, N.A. Vatolin, B.D. Khalezov and E.A. Zelenin

*Address all correspondence to: harin-ei@mail.ru

Institute of Metallurgy, Ural Branch, Russian Academy of Sciences, Yekaterinburg, Russia 


\section{References}

[1] Korovin, S.S., Bukin, V.I., Federov, P.I., et al., Redkie i rasseyannye elementy (Rare and Dispersed Elements), Moscow: MISiS, 2003, vol. 3.

[2] Zelikman, AN. and Meerson, G.A., Metallurgiya redkikh metallov (Metallurgy of Rare Metals), Moscow: Metallurgiya, 1973.

[3] Krcmenetskii, A.P. and Shaderman, F.I., Two ways to wealth, Met. Evrazii, 2000, no. 3, p. 130.

[4] Palant, A.A., Troshkina, D., and Chekmarev, A.M., Metallurgiya reniya (Metallurgy of Rhenium), Moscow: Nauka, 2007.

[5] Zelikman, AN., Molibden (Molybdenum), Moscow: Metallurgiya, 1970.

[6] Lebedev, K.B., Renii (Rhenium), Moscow: Metallurgizdat, 1963.

[7] Levin, V.Ya., Antonova, L.G., Samsonov, A.V., et al., Geology and specific features of ore genesis in the Yuzhno-Shamciskoe. molybdenum deposit in the Middle Urals, Geol. Rudn. Mestoroz) \d., 1995, vol. 37, p. 530.

[8] Gillerbrand, V.F., Prakticheskoe rukovodstvo po neorganicheskomu analizu (Practical Guide to Inorganic Analysis), Moscow: Goskhimizdat, 1960.

[9] Vatolin, N.A., Khalezov, B.D., Kharin, E.I., and Zelenin, E.A., Rhenium recovery from molybdenum concentrates and industrial products: state of the art and outlooks, "Fundamental'nye i prikladnye problemy nauki, " Trudy I Mezhdunarodnogo simpoziuma, (Proc. 1st Int. Symp. on Fundamental and Applied Problems of Science), Moscow, 2010, vol. 2, p. 132.

[10] Vitolin, N.A., Khalezov, B.D., Lobanov, V.G., and Zelenin, E.A., RF Patent 2393253. Byull. Izobr., 2010, no. 18. 